\title{
NCPDP Strength Unit of Measure Terminology
}

National Cancer Institute

\section{Source}

National Cancer Institute. NCPDP Strength Unit of Measure Terminology. NCI

Thesaurus. Code C89509.

A terminology subset for NCPDP that describes a dosage form strength (e.g., $250 \mathrm{mg}$, $250 \mathrm{MG} / 5 \mathrm{ML}$ ) a delivery rate (e.g., $12 \mathrm{mcg} / \mathrm{hr}$ ), a dosage form concentration (e.g., 0.05 $\%, 1 \%$ ), the dosage released from a single delivery device actuation (e.g., 90 mcg [implied as per inhalation], 5 grams), the days supply or quantity in a package (e.g., 28 day, 60 grams). 